\title{
Der Beschaffungsmarkt und seine Mechanismen
}

\author{
Von Manfred Lensing
}

Inhaltsverzeichnis

A. Einfürung Seite

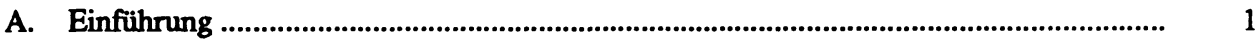

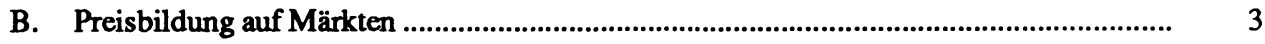

I. Der Markt ........................................................................................................... 3

1. Markt und Wettbewerb ........................................................................................ 3

2. Entwicklungen auf Märkten ............................................................................... 5

3. Märkte des Unternehmens ............................................................................... 6

II. Unterschiedliche Rahmenbedingungen auf Märkten ............................................... 9

1. Volkswirtschaftliche Rahmenbedingungen ..................................................... 9

2. Wirtschaftssysteme ........................................................................................ 9

3. Reglementierte Märkte ................................................................................. 10

4. Marktformen ............................................................................................. 11

III. Preisbildungsmechanismus .............................................................................. 13

1. Preisbildung auf Märkten mit vielen Anbietern und Nachfragern ....................... 13

2. Märkte im Ungleichgewicht ............................................................................... 15

3. Weitere Preisbildungsmechanismen bei ausgewählten Marktformen .................. 17

4. Einflußfaktoren auf die Preisbildung in der Praxis des Einkäufers ....................... 17

C. Methodischer Aufbau einer Beschaffungsmarktforschung (BMF) ................................. 19

I. Beschaffungsmarkterkundung und Beschaffungsmarktforschung ........................... 19

II. Ziele und Aufgabenstellungen der Beschaffungsmarktforschung ............................ 20

1. Beschaffungsmarketing und Beschaffungsmarktforschung als Strategie ............. 20

2. Ziele und Aufgaben der Beschaffungsmarktforschung in der täglichen Einkaufspraxis

III. Informationsgewinnung durch Beschaffungsmarktforschung .................................... 23

1. Methoden der Erhebung von Marktinformationen ............................................. 23

a) Primär- und Sekundärforschung ................................................................. 23

b) Field und Desk Research ......................................................................... 24

c) Demoskopische und ökoskopische Erhebungen ............................................ 24

2. Bestimmungsgrößen für den Informationsbedarf ............................................... 25

3. Überblick über wichtige Informationsquellen .................................................... 26

a) Informationsquellen innerhalb des eigenen Unternehmens .......................... 26

b) Informationsquellen außerhalb des eigenen Unternehmens ........................... 27

c) Messen und Ausstellungen als besondere Form der Informationsgewinnung . 28

4. Informationen und ihre Auswertung und Präsentation .......................................... 30

a) Marktanalyse ...................................................................................... $\quad 30$

b) Marktbeobachtung ................................................................................. 30

c) Marktprognose ............................................................................................ 32 
5. Instrumente zur Informationserhebung, -bearbeitung und -auswertung

D. Untersuchungsobjekte der Beschaffungsmarktforschung ............................................... 35

I. Kriterien zur Auswahl der Untersuchungsobjekte .................................................... $\quad 35$

II. Darstellung einzelner Untersuchungsobjekte .......................................................... 36

1. Produkt oder Leistung .............................................................................................. 36

2. Marktstruktur ................................................................................................. 37

3. Marktbewegungen und -entwicklungen ............................................................. 38

a) Dynamik von Märkten ..................................................................................... 38

b) Konjunkturelle Marktveränderungen ........................................................... 39

c) Internationalisierung der Beschaffungsmärkte ........................................... 40

4. Lieferant .................................................................................................... 41

5. Preise und Kosten ..................................................................................... 42

6. Sonstige Untersuchungsobjekte ...................................................................... 44

E. Organisatorische Einbindung der Beschaffungsmarktforschung im Einkauf ................... 46

I. Beschaffungsmarktforschung als Stabs- oder Linienfunktion ................................... 46

II. Datenverarbeitung als Instrument der Beschaffungsmarktforschung ........................ 48

F. Zusammenfassung und Ausblick ................................................................................... 50

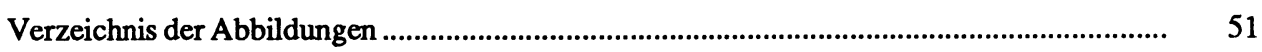

Lösungen der Aufgaben zur Selbstüberprüfung ..................................................................... 52

Stichwortverzeichnis .............................................................................................. 55 